The Boundary of Corporate Social Responsibility Reporting: The Case of the Airline Industry

Dr. Kate Ringham, Oxford School of Hospitality Management, Oxford Brookes

University, Gipsy Lane, Headington, Oxford, OX3 0BP, UK, kringham@brookes.ac.uk, +441865 483827 [corresponding author]

Dr. Samantha Miles, The Oxford Brookes Business School, Oxford Brookes University, Gipsy Lane, Headington, Oxford, OX3 0BP, UK, svmiles@brookes.ac.uk 


\title{
The Boundary of Corporate Social Responsibility Reporting: The Case of the Airline Industry
}

\begin{abstract}
This paper explores the boundary of Corporate Social Responsibility (CSR) reporting. We present a conceptual analysis of boundary definitions and an empirical analysis of boundary construction in practice. Boundary is an important, yet under-analysed concept, as it specifies the limits of accountability: what activities stakeholders may expect an organization to report on. The adoption of a narrow boundary will omit many impacts from disclosure, reducing the usefulness of CSR reports. Historically boundary has been unchallenged, based on financial reporting concepts of control and significant influence. Recent thought suggests boundaries should vary on an issue-by-issue basis rather than being applied universally on an organizational level. A thematic analysis of $15 \mathrm{CSR}$ reporting guidelines was undertaken to identify what constitutes boundary within CSR reporting. The emergent 40 determinants were ordered and classified into three boundary constructs: Reputation Management; Ownership and Control; Accountability. Reporting content of 35 airline companies was coded according to these constructs, on an issue-by-issue basis (using relevant Global Reporting Initiatives (GRI) indicators). Correlation analysis indicates: the adoption of selective, narrow definitions of boundary; an inverse relationship between boundary determination and stakeholder consultation, and; companies that claim compliance to GRI, on average, select narrower boundaries than non-signatories. Implications for research and for practice are highlighted.
\end{abstract}

Keywords: Boundary; Corporate Social Responsibility Reporting; Airline Industry; Content Analysis; Global Reporting Initiative 


\section{Introduction}

Boundary constructs adopted within corporate social responsibility (CSR) reporting are fundamental to the nature, scope and content of reporting. The boundary adopted determines the limits of an organization's accountability, and therefore the limits of what activities stakeholders may reasonably expect an organization to report on. There has been much debate regarding the extent to which CSR reporting is an appropriate mechanism by which business can be held to account (e.g. Cooper and Owen, 2007; Gray, 2006; Milne and Gray, 2013; Owen, 2008), however, current discourse relates to relevance and materiality (Khan, Serafeim and Yoon, 2016) rather than boundary constructs.

For financial reporting, the boundary is dominated by the legal entity, stemming from the concept of management control. This has been extended to CSR reporting as a largely unchallenged assumption (Pesci and Andrei, 2011). Whilst critical scholars argue that the adoption of financial reporting concepts, without significant modification, is inappropriate for CSR reporting given the complexities involved (Gray, 2006; O’Dywer, 2000), the specific issue of boundary determination within CSR reporting has received little academic attention. Is this problematic? We argue that it is. Given that much CSR reporting is voluntary, managers are able to determine the boundary for their individual reports, for specific reporting issues, and for the scope of assurance, if undertaken. This enables managers to manipulate the information provided by emphasising certain impacts and excluding others from the report and/or the assurance statement. This significantly reduces the transparency and reliability of information, the ability to benchmark performance and the ultimate usefulness of the reporting.

Whilst historically overlooked, the issue of boundary determination is gaining in prominence. 
GRI (2013), for example, challenged the status quo by encouraging managers to view boundaries on an issue-by-issue basis, rather than adopting an organization-wide perspective. It argued that boundaries should vary according to the aspects reported. The extent to which signatories to the GRI are following this advice is currently unknown. Materiality and boundary are somewhat conflated by the GRI, which advocated that organizations should focus attention to reporting on CSR issues that are material for their industry, and to extend boundaries accordingly. We view these decisions as distinct. Materiality is a threshold principle in deciding whether to report or not report. Boundary determination is a subsequent decision impacting how material issues are reported on. Boundary setting may be influenced by materiality but is also subject to consideration of managerial intention, stakeholder concerns, controllability or responsibility of the issue, desires for transparency and accountability, availability of data and associated accounting methodologies.

The aim of this paper is to analyse the concept of the boundary of CSR reporting. The paper begins with a review of organizational boundary and accountability. Boundary has been analysed in two ways. Firstly from the perspective CSR reporting guidance providers and, secondly, how it has been interpreted in practice by corporations and this approach is reflected in the following section. The methodology is then outlined. Given that there is not agreed definition of boundary within CSR reporting, a thematic analysis of 15 different sets of CSR reporting guidance has been undertaken to extract potential determinants of boundary identification. A wide range of guidance was evaluated, including all iterations of the Global Reporting Initiative (GRI), the International Integrated Reporting Framework (IIRF) and the Climate Disclosure Standards Board Standards (CDSB). The emergent boundary determinants $(n=40)$ were then sorted and classified into three boundary concepts. A quantitative coding framework to assess reporting practice was then constructed using the three boundary definitions identified and applied, using content analysis to a sample of CSR 
reports $(n=35)$. In order to test the extent to which aspect boundaries have been adopted the content analysis focused on disclosure in relation to 22 GRI social, environmental and economic indicators. The indicators selected represent those that are firstly material to the aviation sector, and secondly, are capable of being reported on across a range of boundary settings. The findings from the content analysis are then detailed. These are analysed quantitatively, using correlation analysis, and qualitatively to illustrate examples of how the range of boundary constructs have been adopted. Finally conclusions are drawn before suggestions for future research are presented.

The global airline industry has been selected as the focus for analysis. This sector makes a significant contribution to the global economy (\$2.7 trillion including direct, indirect, induced and the catalytic effects of tourism) (IATA, 2016a). It also has significant social and environmental impacts, which left unchecked will increase with growth in scheduled passenger numbers, which rose by $7.4 \%$ in 2015 and $6.2 \%$ in 2016 (IATA, 2016b). In addition to adverse impacts on biodiversity in local habitats (CAA, 2015) and noise pollution on local communities situated under flight paths and close to airports (Cowper-Smith and de Grosbois, 2011), airline emissions contain many of the greenhouse gases (GHG) associated with climate change (Chang and Yeh, 2016; Cowper-Smith and de Grosbois, 2011; Kuo, Kremer, Phuong and Hsu, 2016). Despite being responsible for such significant direct and indirect impacts, CSR reporting for the airline industry remains inconsistent and incomparable, with little social reporting (Cowper-Smith and de Grosbois, 2011), and of poorer quality than other high-polluting industries, such as mining and utilities (KPMG, 2015). This is consistent with the disclosure-performance gap recognised elsewhere in the hospitality sector (Font, Walmsley, Cogotti, McCombes and Hausler, 2012; de Grosbois, 2012). 


\section{Organizational Boundary and Accountability}

The definition of boundary is a central concept for CSR reporting as it determines the point at which the organization is differentiated from its environment or from society. It defines which elements and activities are included as part of the organization and those to be excluded or considered externalities. This directly determines the content, scope and breadth of the report as the adoption of different boundary definitions will make some activities more visible than others (Llewellyn, 1994).

Boundary determination is distinct from the assessment of the materiality of an issue. CSR reporting can be viewed as a two stage process in which the first stage is to decide whether to report on an issue or not. Ideally this should be based on a materiality assessment in which reporters differentiate material from non-material issues, ensuring that disclosure covers all material aspects. The GRI (2013) advocated that companies demonstrate this through the creation of a materiality matrix in which material issues identified by stakeholders are juxtaposed against those identified by the organization. For example Air France identified, amongst others, safety, biofuel, noise and air quality, health and safety and $\mathrm{CO}_{2}$ reduction as material issues using this approach. This creates the expectation that these aspects will be included in the CSR report.

The second stage of the production of a CSR report requires the determination of a reporting boundary, either for the organization as a whole, or on an issue by issue basis. This process is not particularly transparent. Management is free to define boundaries and consequently boundary setting is not a neutral activity, being subject to manipulation (Archel, Fernández, and Larrinaga, 2008) and managerial capture (O’Dywer, 2003; Sethi, Martell and Demir, 
2017). Management may use the definition of boundary to manipulate the image presented and so constructs a "social picture" of the organization by defining what the organization can reasonably be held responsible, or accountable, for. Consequently, there is a moral dimension to decisions made with respect to boundary definition. Boundary determination may also be influenced by practical considerations such as the availability of advanced accounting methodologies to measure and monitor intangible impacts, the lack of an acceptable unit of measurement for social, environmental and ethical impact and cost considerations relating to data collection and information systems management.

Boundary has been robustly debated within organizational studies. Grandori (2000), for example, differentiated knowledge-based boundaries, proprietary boundaries, internal contractual boundaries and areas of influence, whereas Llewellyn (1994) identified physical/productive, financial, psychological, legal and temporal organizational boundaries. Morgan (1986), meanwhile, distinguished between closed, or egocentric, organizational systems, in which boundaries are impermeable to the surrounding environment, and open systems, characterised by a permeable interface between the organization and society/environment which manages exchanges of natural resources, capitals and information in order to achieve equilibrium. There are other approaches, for instance Llewellyn's (1994) and Gowthorpe's (2009) explorations of the idea of boundary maintenance within the financial reporting framework, in which boundaries are not assumed but are achieved through individual action and function as both thresholds and binding structures.

The academic community has paid little attention to the definitions of boundary within the field of CSR reporting, despite its importance. Pesci and Andrei (2011) and Archel et al. (2008) are notable exceptions. Pesci and Andrei (2011), exploring boundary construction of 
companies listed on the Milan stock exchange, recommended that the boundary for CSR reporting should reflect the financial reporting boundary to ensure consistency. This approach has received criticism given the incongruence between the aims, objectives and scope of CSR reporting compared to financial reporting (Gray, 2006; O'Dywer, 2000). Archel et al. (2008, p.115) focused on the boundary setting in the GRI (2002) compliant CSR reports of 57 companies across 19 countries. Content analysis was used to analyse the adoption of either an "operational boundary", relating to upstream and downstream influence, or an "organizational boundary" reflecting operational and financial control and significant influence through ownership. Organizational boundaries were analysed using two variables: whether extended organizational boundaries were set, and whether disclosure enabled the reader to assess how boundaries were set. Operational boundaries were assessed using five variables: completeness of disclosure on indirect impacts specified by the GRI, analysed according to core or additional performance indicators, and misreporting of direct impact as indirect impact (core or additional performance indicators). Their findings confirmed the establishment of narrow selective boundaries that failed to fully reflect the financial control dimension of boundary and provided limited reporting of indirect impacts. Given the importance of this issue, and the scarce attention received to date, there is considerable scope for theoretical and empirical investigation on boundary determination and the associated implications of for CSR reporting.

\section{The Concept of Boundary within CSR Reporting Guidance and Practice}

CSR reporting is supported by an array of reporting guidance, which seeks to provide checklists, principles, toolkits and/or reporting formats for organizations wishing to disclose their CSR impacts. There is no generally accepted definition of boundary adopted across 
guidance. The importance given to discussing boundary and the subsequent definitions adopted differ between guidance depending on the aims and objectives of the guidance providers and the intended audiences of the reports. This is because the guidance providers emanate from a diverse range of organizations which have varied socio-political interests. For example, UNGC (2009) was developed as a means through which business could show support for the UN Sustainable Development Goals. Wide social objectives are evident in the guidance published by international independent standards organizations (e.g. GRI, 2000; 2002; 2006; 2013; 2016), intergovernmental organizations (e.g. OECD, 2011; UN 2006; 2008; 2009; 2011), charities/not-for profit organizations (e.g. Business in the Community, 2005; SASB, 2016) and environmental consultants (e.g. AccountAbility, 2008). These institutions would be expected to adopt broader definitions of boundary when compared to investor-focused (e.g. ICGN, 2008, FRC, 2009; IFRS, 2010) or corporate-focused guidance providers (e.g. CDSB, 2012; 2013; 2015; IIFR 2013), as the latter are more concerned with risk management, governance and compliance than accountability.

Given the voluntary nature of guidance, guidance setters frequently work directly with interest groups to achieve acceptance via consensus building (Aras and Crowther, 2008). Interest groups seek to influence the nature of the guidance provided and the boundary specified by promoting their vested interests and political agendas, which may differ between parties. Corporates, for example, may aim to influence disclosure boundaries as a means of mitigating the risk of extensive regulation (Fortanier, Kolk and Pinkse, 2011), whereas NGOs may aim to increase accountability across indirect impacts. Whilst guidance may be seen as a means to regulate the power of corporations (de Jonge, 2011), shareholder groups and corporates appear to have the most powerful voice in this process as their interests are reflected to a much greater extent than secondary or tertiary stakeholders. Etzion and Ferraro 
(2010), for example, highlighted that the reporting principles in GRI closely reflect the qualitative characteristics of accounting information identified by the Financial Accounting Standards Board, including reference to the accounting concepts of materiality (GRI, 2000), control (GRI, 2006) and influence (GRI, 2006). It has been suggested by Brown, de Jong, and Levy (2009) and Etzion and Ferraro (2010) that this similarity is intentional and may be a key reason for the success of the GRI.

CSR reporting in practice is influenced by guidance provision, but, as a voluntary activity, the adoption of guidance and the definition of boundary used are subject to management discretion. Management is free to cherry pick between, and within, guidance in order to claim compliance and receive associated credibility (Archel et al., 2008); this is particularly relevant for guidelines which specify narrow forms of reporting as a starting point (see ISO (2010); UNCG (2009)). The GRI is progressive with respect to boundary, and has acknowledged the importance of the definition of the boundary from the outset; reporting organizations are advised to clearly and explicitly define the boundary conditions adopted. Unfortunately, however, this is not a condition of compliance, resulting in varied practice which hampers comparability and consistency, and facilitates the publication of reports driven by reputation management (Bebbington, Larrinaga and Moneva, 2008). Researchers have paid scant attention to boundary definition within reporting CSR reporting guidance. We address this through an in-depth analysis of the concept of boundary across 15 sets of guidance.

With respect to CSR reporting practice, most examples are considered to represent selflaudatory reflections of impact based on constricted narrow boundaries. Such reports ignore most, if not all, indirect impacts and many direct impacts that should be reportable under a 
strict adherence to the entity concept. There are some welcome exceptions. Puma (2011), for example, disclosed that indirect impact of Tier 2-4 suppliers accounted for $85 \%$ of the group's environmental impact. This was based on the boundary definition: "from the production of raw materials, through the manufacturing process, and up until the point of sale" (Puma, 2011, p.11). Puma's 'Environmental P\&L' challenged the status quo but it is not without issues. Puma required a completely new accounting methodology to operationalise this, which it developed at great cost in conjunction with PricewaterhouseCoopers LLP and Trucost PLC. Furthermore, due to costs and complexity involved, the scope of application was restricted to a single product line, thereby narrowing the boundary in practice. Alternative accounting methodologies have been developed, such as the footprint methodology. These enable the reporting of direct and indirect usage in the supply chain, but are generally limited, underdeveloped, and are not transparent if protected via patents. When companies adopt advanced methodologies, there is often a lack of transparency concerning the details of the implementation or the methodology itself thereby limiting the comparability of reporting. Empirical investigations of boundary within the context of CSR reporting are exceedingly limited. This paper aims to add to previous studies such as Archel et al., (2008) through an evaluation of practice within the global aviation sector.

\section{Methodology}

A two stage methodology approach was adopted. Stage 1 relates to the thematic analysis of CSR guidance provision. This was undertaken to identify attributes of boundary determination. The boundary determinants were analysed and classified, leading to a range of boundary definitions. The boundary definitions were then used, in stage 2 , in the 
construction of the coding framework to be used in the content analysis of CSR reports. Stage 2 also involved identifying relevant GRI indicators against which disclosure could be assessed. The content analysis resulted in both qualitative and quantitative data for analysis. Detailed description of these stages is presented below.

\section{Stage 1. Thematic Analysis of Guidance Provision}

Given the lack of an accepted definition of boundary and the lack of academic attention devoted to boundary setting within CSR reporting, exploratory conceptual analysis of CSR reporting guidance was undertaken to determine, collate and analyse extant thinking on boundary construct. The aim of the thematic analysis was to therefore to extract 1 . Boundary definitions; 2. Determinants of different boundary settings, and; 3 . Changes in definitions and determinants over time.

The authors selected 23 sets of CSR reporting guidance, designed to reflect a range of originating organizations, objectives and stakeholder focus and to ensure inclusion of a global and national focus. Eight sets of guidance failed to discuss boundary and so were excluded from analysis (Accountability, 2008; Business in the Community, 2005; EU, 2011; FRC, 2009; ICGN, 2008; OECD, 2011; UNCTD, 2008; UN, 2006). One exception relates to SASB (2016). Despite having no reference to boundary, the SASB presented five dimensions to guide organizations when determining materiality, such as direct financial impacts, legal drivers, industry norms, stakeholder concerns and opportunities for innovation. When viewed from a boundary determination perspective, these dimensions provide further insight, thereby aiding in understanding of potential boundary settings. This returned 15 sets of guidance for analysis.

All references to "boundary" and relevant text were then extracted and inputted into a 
spreadsheet (a summary is presented in Appendix 1). The researchers independently reviewed this dataset to identify themes within the data that are important for the description of "boundary". The resulting list of themes were analysed for i) frequency of themes across the guidance provision; ii) co-occurrence of themes across the dataset to determine relationships and subthemes; and iii) characteristics relating to common categories for boundary determination. The analysis revealed 40 boundary attributes (underlined in the text below) which have been filtered, ordered and categorised into three definitions of boundary: i) reputation management; ii) ownership and control; and iii) accountability.

\section{i) Reputation Management}

The narrowest definition of boundary is labelled "reputation management", which encompasses 12 boundary attributes that were highlighted by 7 of the 15 guidance providers. Bebbington et al., (2008) argued that CSR reporting contributes to an organization's legitimacy and reputation. This is achieved through managerial-determined boundaries driven by "opportunity" (IIRC, 2013; CDSB, 2015) "competitive advantage" and "industry expectations" (SASB, 2016), "risk assessment" (CDSB, 2015; IIRC, 2013; SASB, 2016) or may be in response to a legitimacy breach (Lindblom, 1994). Within a reputation management boundary setting content is selected from a particular "company" (GRI, 2000), "business unit" or "geographic region" (CDSB, 2013). Companies may use stakeholder engagement to enhance its reputation by using CSR reporting to address "stakeholder concerns" as evident in SASB (2016) or engage in "public policy dialogue" (IFRS, 2010). In particular CSR reporting can be used to promote selective examples of "community interaction, social investment and philanthropy activities" (UNGC, 2009) in order to enhance reputation.

We define a management reputation boundary as the narrowest conceivable 
reporting boundary characterised by self-laudatory, selective cherry-picked content.

\section{ii) Ownership and Control}

Advice to adopt the "financial accounting" boundary was given by $73.3 \%$ of the guidelines. The financial accounting boundary is clearly defined within legislation (e.g. Companies Act 2006 for the UK) and within accounting and auditing standards to determine the boundary of the consolidated financial statements. This conceptualisation of boundary is based on the financial reporting entity and limits reporting to operations over which the organization has “ownership” (GRI, 2002), “control” (CDBS, 2013; GRI, 2000; 2002; 2006; UNGC, 2009) or “significant influence” (CDBS, 2013; GRI, 2016; IIRC, 2013; UNCG, 2009). Ownership may be derived from "equity shares" or investment in "joint ventures" and "partnerships", whereas operational or financial control (CDSB, 2013), as evident within 'groups' (GRI, 2000) consisting of "parent" companies (CDSB, 2013) and "subsidiaries"(GRI, 2006; CDSB, 2013) is not conditional on majority shareholding. The conceptualisation of boundary based on financial reporting suggests the adoption of the time frame associated with financial reporting. This is an historic time period and so there is no recognition of any medium/longterm indirect impacts on ecosystems or society. The boundary associated with ownership and control can be summarised as reporting on all "direct impacts" (SASB, 2016) within the "organizational boundary" (GRI, 2013) to ensure capture of "core activities" (UNGC, 2009) as well as any activities over which a "significant influence" (CDSB, 2013; GRI, 2016; IIRC, 2013; UNGC, 2009) is exercised. Adoption of a definition of boundary based on ownership and control should lead to fuller reporting than one based on a reputation management boundary.

We define an ownership and control boundary as an organizational boundary 
based on significant influence and direct impact derived from ownership and control.

\section{iii) Accountability}

The final definition of boundary has been labelled 'Accountability'. The reporting boundary can be extended beyond that captured by 'ownership and control' in three ways. Firstly the organizational boundary can be extended to include the "operational boundary" (GRI, 2006; CDSB, 2013) through the value chain to include activities "outside of the organization" (GRI, 2013; CDSB, 2015) including "upstream" ("supply chain”, "outsourced activities” and "subcontractors") and "downstream" ("life cycle", "distributors and users") (CDSB, 2012, 215; GRI, 2000, 2006, 2011; UNGC, 2009) impacts. Secondly, boundary can be extended through the recognition of "responsibility" (CDBS, 2013; 2016) of indirect impacts that are unambiguously traceable to an organization's activities. This definition of boundary aligns with the purpose of CSR disclosure as "the outcome of a sense of accountability to stakeholders, driven by a genuine interest in enhancing transparency" (Michelon, Pilonato and Ricceri, 2015, p.62). This interpretation should incorporate a holistic approach to dealing with "stakeholder concerns" (SASB, 2016) and include genuine engagement with a wide range of stakeholders. Thirdly, the boundary can be extended by recognising that actions today, or in the past, have implications for the future, 'near or medium term impacts' (SASB, 2016). A boundary based on accountability can therefore be extended by any combination of these factors, with the widest possible boundary definitions incorporating all three dimensions: value chain, responsibility and time.

We define an accountability boundary as one which widens the reporting remit through time, stakeholder responsibility or by acknowledging the organization's indirect impacts through the value chain. 
The attributes associated with each definition are summarised in Table 1.

Insert table 1 here

\section{Stage 2 Content Analysis of CSR Disclosure}

Sample

The sample comprises the most recent (2012-2015) CSR reports of all corporations categorised by Corporate Register, a world-wide CSR directory, with an industry tag of “airline”, as of December 2016. This returned 35 companies for analysis (Table 2).

[Insert Table 2 here]

\section{Coding Framework}

Content analysis was used to analyse the boundary adopted within the CSR disclosure of the 35 aviation companies selected. Content analysis is a widely used method to analyse CSR disclosure (see Archel et al., (2008) for application and, Hammond and Miles (2001) and Milne and Alder (1999) for a discussion of approach and methodological issues). The qualitative thematic analysis of CSR guidance (detailed above) was used as the basis for the coding framework devised using a disclosure index of 0-3: No disclosure (0); Reputation management (1); Ownership and/or control (2); Accountability (3).

\section{Disclosure Indicators}

In evaluating boundary we have followed the principles outlined in GRI (2016) in which 
boundary construct is evaluated from a material topic or aspect perspective, rather than assuming a single approach to boundary setting at the organization level. This necessitated examination of boundary setting from the individual social, environmental or economic aspect for each company. In doing this we considered the 46 standard disclosure indicators proposed by GRI (2013). A range of aspects $(n=24)$ were removed from analysis due to either i) a restricted boundary specified in the reporting requirement, or ii) a lack of relevance to the aviation sector. For example, economic indicator EC1 "direct economic value generated and distributed" may be interpreted under boundary conditions 1 (reputation management) if selected direct economic value is disclosed, or 2 (ownership and control) if economic value is demonstrated for all operations within the organizational boundary, but not 3 (accountability), since by definition disclosure is restricted to "direct economic value" only. Likewise, HR8 "incidents of violations involving the rights of indigenous people", whilst capable of an extended boundary approach, is not a material issue for the aviation industry and so was excluded on this basis. Both researchers independently assessed all 46 indicators for both materiality of issue and for potential boundary extension. Justification for decisions in relation to materiality is included in Table 3, in which the 22 indicators selected for evaluation are detailed and mapped against GRI (2016) indicators (operational from 2018) . These are grouped into five variables: LABOUR (Labour practices and decent work indicators LA6, LA14, LA15); SOCIETY (Society indicators SO1-2; SO9-10); (RIGHTS) (Human rights indicators HR4-5; HR10-11); (ECON) (Economic indicators EC7-9), and; (ENVIRN) (Environmental indicators EN4; EN12; EN16-17; EN30; EN32).

CSR reports $(n=35)$ were downloaded, independently interrogated by both researchers to extract relevant disclosure (22 GRI indicators), and coded according to boundary levels determined from the thematic analysis of CSR guidance. Data was extracted into a 
spreadsheet for analysis. Both researchers independently assessed the boundary inferred on an aspect-by-aspect basis (scale $0-3$ as above).

[Insert Table 3 here]

\section{Additional Variables}

Data were also gathered on two further variables that were subjected to statistical analysis: BOUND and STAKE. BOUND identifies whether boundaries were specified in the report and, if so, on what basis to establish whether this is consistent with application of aspect boundaries. A scale of 0-3 was adopted (as above). STAKE identifies the number of stakeholders each company consulted with in the determination of the reporting content. Friedman and Miles (2006) proposed a ladder of stakeholder engagement that suggested a continuum of engagement levels ranging from the use of stakeholder engagement as a legitimating tool to change expectations of stakeholders, through to forms of engagement in which stakeholder concerns are embedded into corporate decision-making. This would indicate that engagement at the lower levels of the ladder would be associated with reputation management and engagement at the higher levels with accountability. Stakeholder engagement is considered to be a fundamental accountability mechanism (Bellantuono, Pontrandolfo and Scozzi, 2016) suggesting that increased stakeholder consultation should result in wider boundary constructs, as genuine efforts to engage with an accountability boundary would necessitate comprehensive engagement with a wide range of stakeholders. Conversely, the adoption of a reputation management boundary can be exercised without stakeholder engagement, or with pseudo-stakeholder engagement. Using this logic, the number of stakeholders consulted in the CSR reporting process $(0-11)$ has been taken here as a proxy for engagement commitment. 
Finally it was noted whether or not the airline company claimed compliance with the GRI reporting framework to explore whether compliance was associated with wider boundary definitions across material aspects, as advocated by the GRI (2013).

\section{Results and Discussion}

\section{Content Analysis of CSR Reports in the Airline Sector}

All variables were divided by the maximum permitted score for each so that indicators are expressed on a $0-1$ score, enabling overview of the cumulative comparisons of variables (ECON, ENVIRN, LABOUR, RIGHTS, SOCIETY) in which the number of disclosure indicators varied from 3 to 7 . Consequently, a reputation management boundary is indicative of results within the range $0-0.33$, an ownership and control boundary is represented by results in the range $0.34-0.66$ and accountability from 0.67 to 1.0 .

The boundaries defined by the airline companies sampled were predominantly based on a reputation management boundary, as indicated by the low mean values of the five variables tested (Table 4). This is consistent with the findings of Kuo et al. (2016) who concluded that the most significant motivator for CSR disclosure in the airline industry was reputation management.

[Insert Table 4 here]

The use of the accountability boundary definition for the 22 GRI was found to be limited. The widest boundaries adopted related to RIGHTS, however the mean score $(0.425 \pm 0.372)$ was still indicative of a boundary setting based on ownership and control (0.34-0.66). FAI (2014, p.44), for example provided very limited disclosure (coded as $0=$ no disclosure) 
relating to its supply chain: "Due to the wide scope of the supply chain and the associated complex data situation, we were not able to estimate the total number of suppliers in the supply chain". In comparison, Singapore Airlines (2015, p.25) appears far more progressive (coded as $3=$ accountability):

"We have a Code of Conduct which we expect all our suppliers to comply with. Based on the principles of the United Nations Global Compact related to Human Rights, Labour, the Environment and Anti-Corruption, and taking into account operational, social and environmental issues, the Code of Conduct was developed in accordance with our business values and with the intention of promoting sustainable development".

Nevertheless, there was a lack of disclosure regarding the implementation and impact of this code of conduct.

A one-sample t-test was run to determine whether the disclosure score for the sample was different to normal, as defined by a disclosure score of 0.4 (Archel et al., 2008). The disclosure scores were normally distributed (Shapiro-Wilk test) and there were no outliers. The t-test indicated two significant variables (SOCIETY and ENVIRN). ENVIRN, for example was significantly lower by 0.106 (95\% confidence level, from -0.181 to -0.04$)$ than the normal disclosure level of 0.4 .

GRI (2013) encourages managers to view boundaries on an aspect-by-aspect basis, as boundaries vary according to the aspects reported. Consequently, in addition to the descriptive statistics, a disclosure index for all 22 GRI indicators was generated to explore aspect boundary setting adopted by the industry. The results are presented in Figure 1. [Insert figure 1 here] 
Boundary was found to vary from issue-to-issue, which may indicate an aspect boundary approach. To differentiate this from cherry-picking an overview of the most significant impacts was undertaken. There was little evidence of the most widespread impacts for the aviation sector being reported against wider boundaries. For example, noise pollution is a major concern for communities living near airports or under flight paths and is therefore rated as a significant indirect impact by stakeholders. Nevertheless disclosure for SO2 (negative impacts on local communities) was synonymous with a weak ownership and control based boundary $(0.3904 \pm 0.4678))$, with only six airlines extended the boundary beyond this. Comparing this to the disclosure relevant to HR4 (freedom of association and collective bargaining), boundary setting was significantly higher $(0.5238 \pm 0.4070)$ but in relation to the modern slavery act rather than collective bargaining, which is more of an issue for this sector. The widest boundary identified relates to EN16, indirect GHG emissions (scope 2) (0.685 \pm 0.420) (note that descriptive statistics for individual indicators are not reported in table 4). Whilst this is a major concern for the airline industry, the evidence of a wider reporting boundary may be indicative of the availability of advanced measurement and accounting methodologies developed in response to political attention to cutting global carbon emissions, rather than an intentional widening of the boundary for accountability purposes.

The qualitative analysis revealed some interesting differences in approach. Consider, for example, LA6, type of injury, rates of injury, etc. Nine companies $(26 \%)$ did not disclose any data for this indicator. For example, EasyJet PLC (2014, p.37) (coded as $0=$ no disclosure):

"we capture and monitor all incidents and injuries to our people and passengers wherever they happen, the way in which we have reported on our operating safety does not align with other industries' reporting and is not in a format familiar to many 
of our stakeholders".

The majority of companies (63\%) adopted a control/ownership boundary (coded as 2), for example GOL (2014) reported data that "includes domestic bases only and employees subject to CLT and apprentices. Outsourced employees are monitored by outsourcing companies." Only two companies, Etihad and AeroMexico adopted an accountability boundary (coded as 3) for this indicator, for example, AeroMexico (2014, p.29) reported on: "Occupational diseases of workers and independent contractor staff working at Aeromexico facilities, by region and gender".

The average boundary adopted for ENVIRN indicators was narrow $(0.294 \pm 0.206)$. For example, in relation to EN12 Air New Zealand (2015, p.22) stated:

"In the past three years we have partnered with the Department of Conservation (DOC) to protect and enhance New Zealand's natural environment. Our focus has been on investing in biodiversity projects on New Zealand's Great Walks - an iconic part of our country's tourism offering”.

This kind of strategic alliance, whilst working towards protecting the environment, is predicated on the commercial benefits resulting from reputation management (coded 1) rather than an accountability perspective (coded 3 ). The narrowest boundary definition was adopted with respect to EN4, "energy consumption outside of the organization" $(0.095 \pm 0.250)$. In practice, energy consumption outside of the organization is a difficult impact to measure and so boundary construct may be heavily influenced by a lack of available accounting methodologies. For example, Air France KLM (2014, p.39) acknowledged its impact, but there was no disclosure (coded 0) due to the lack of measurement: "Air transport affects biodiversity indirectly through CO2 emissions, as well as through impact related to inflight food production". 
ECON indicators were generally neglected, with low levels of disclosure and narrow boundary settings across the industry. For example, under EC8, "indirect economic impacts", Cargolux (2014, p.10) did not interpret this in relation to the entire supply chain, focusing instead only on employment, which thereby represents a narrow interpretation (coded 1) of EC8: "Cargolux is a major employer in Luxembourg and creates many jobs, not only at its home base, but also at many airports and communities around the world". This can be contrasted with AirFrance KLM (2014) which evidences a wider boundary (accountability coded 3) by providing information on indirect upstream and downstream impacts including suppliers " $€ 1.9 b n$ Air France purchases (excluding fuel), $€ 26 b n$ contribution to Dutch GDP" (p. 67) as well as broader impacts on local structural initiatives "The Group is involved in various initiatives to strengthen the economic attractiveness, reputation, international competitiveness, and sustainable development of its hubs...Promoting socio-economic development of Paris-CDG area. Collaborate with more than 340 members...on jobs, housing, economic development, transport and culture...promote destination Amsterdam, improve accessibility, education and sustainability" (p.66)

Airlines complying with GRI (2013) should disclosure all operations with significant actual and potential negative impact on local communities (GRI indicator SO2). Disclosure for this indicator was fairly low $(0.390 \pm 0.468)$ and inconsistent. JetBlue (2014), for example, disclosed that the supply chain is audited for conflict minerals. Conflict minerals is a minor issue for this sector, compared to the impact of noise pollution on local communities, on which JetBlue were silent. This is illustrative of a company appearing to be exercising accountability but in practice the reporting is undermined by the absence of material impacts and so is a reputation management exercise (coded 1). In contrast Virgin Atlantic (2015, p.28) acknowledged wider accountability for noise pollution through an examination of its 
impact on external stakeholders (coded 3): "[the company will] continue to work with airports to make sure we mitigate noise for local communities" and "Our average noise output per aircraft movement was $95.53 \mathrm{~dB}$ in 2014. This is a reduction of $2.07 \mathrm{~dB}$ since our 2012 baseline. This means we're over a third of the way to our 2020 target already".

Correlation analysis was conducted to explore how strongly variables were related to each other. This was explored in the first instance to test whether organizations were adopting aspect boundaries, as advocated by the GRI, or organization-wide boundaries (Table 5). A strong positive correlation is evident between all social indicators (LA, SO and HR), implying that companies do not adopt dramatically different aspect boundaries for social disclosure. Economic disclosure was generally poor, with a very narrow definition of boundary across all airlines compared to other indicators. The correlation between economic and social disclosure was very weak, indicating different boundary conditions between these indicators. This is unsurprising, given the more subjective and ambiguous nature of social disclosure compared to economic disclosure, and the ease of gathering economic data from existing financial reporting systems.

[insert Table 5 here]

Stakeholder consultation is encouraged by guidance provision, particularly the GRI, to help companies identify areas of stakeholder concern and then to use CSR disclosure as a means of managing stakeholder expectations. Stakeholder engagement should be a fundamental step of the reporting process in the determination of materiality and relevance of the information communicated (Manetti, 2011) (stage 1 in the CSR reporting process). The majority of reporters $(54.3 \%)$ made reference to the involvement of external stakeholders in the determination of the boundary of the report. A further $25.7 \%$ of reporters used a 
materiality matrix to present the information resulting from the stakeholder engagement process, although disclosure did not permit an analysis of whether the material issues included in the individual matrices were those actually identified by stakeholder groups or deemed important by management following stakeholder consultation. Ten reporters $(28.6 \%)$ did not did not provide any information regarding stakeholder engagement in the reporting process. The maximum number of stakeholders listed was 11 (Deutsche Lufthansa), the minimum zero (All Nippon, British Airways, Easyjet, JetBlue, Virgin Atlantic, Virgin Australia) and the mean $5.457( \pm 3.32)$.

STAKE was negatively correlated across 4 categories of GRI indicators (LABOUR $\mathrm{r}=-0.128$; SOCIETY $\mathrm{r}=-0.342$, RIGHTS $\mathrm{r}=-0.019$, ENVIRN $\mathrm{r}=0.169)$. This is indicative of engagement being used as a reputation management tool, supporting the findings of Manetti (2011), given that wider stakeholder engagement should lead to the adoption of wider boundaries based on accountability. There is a small positive correlation with ECON $(\mathrm{r}=0.279)$ which indicates that consensus opinion is dominated by financial interests reducing disclosure (the lowest common denominator effect).

The final variable BOUND relates to the extent of the boundary specified by airlines in the creation of their CSR reports. It was expected that disclosure of a wider boundary determination would be positively correlated to a wide boundary application. This was not found to be the case, as only a very weak positive correlation is evident with regards to social and economic disclosure and a very weak negative correlation to environmental disclosure. This exploratory finding suggests a "boundary gap" between the boundary that companies report that they adopt and the boundary adopted in practice, which could be misleading. 
GRI compliance was claimed by 27 of the 35 companies: 14 signatories to GRI v.3 (2011) and 13 to GRI v.4 (2013). Signatories to GRI v.4 (2013), in which aspect boundary determination is encouraged had on average lower discernible boundary definitions across all 22 indicators, as evidenced by mean $0.297 \pm 0.191$, compared to signatories of GRI v.3 (2011) $(0.334 \pm 0.243)$ and companies that were not signatories of the GRI $(0.37 \pm 0.234)$. This indicates that the GRI's objective of widening boundary setting has not been achieved within the airline industry.

Boundary definition varies considerably between companies. Disregarding Chinese Southern Airlines, which failed to report on any of the 22 GRI indicators analysed, the poorest reporters, both in terms of lowest average boundary score and lowest number of indicators reported at level 3 "accountability" were Air China (0.0606 average disclosure; number of level 3 disclosures $=0)$, Xiamen $(0.0758 ; n=0)$ and Thai Airways and Westjet (both 0.1061; $\mathrm{n}=1$ ). The companies reporting the greatest number of indicators on an accountability boundary were Virgin Atlantic $(0.7929 ; n=15)$, TAP $(0.7424 ; n=13)$ and Southwest $(0.7424$; $\mathrm{n}=13$ ), indicating that aspect boundary, as endorsed by GRI (2013) has been applied in a limited number of cases across this sector.

\section{Conclusions}

This research aims to highlight the importance of the definition of the boundary as a central concept for CSR reporting, as it specifies the limits of those activities stakeholders may expect an organization to report on. Nevertheless boundary has received little attention within CSR reporting research. The current research, whilst exploratory, aims to address this gap by presenting a conceptual analysis of boundary definitions and an empirical analysis of boundary construction in practice within the global airline sector (35 companies). 
Given the lack of academic attention to boundary determination, a thematic analysis of how boundary has been constructed within 15 CSR reporting guidelines over time was undertaken to extract boundary definitions, the attributes of different boundary definitions and changes in these over time. This conceptual enquiry revealed a list of 40 themes which were analysed and categorised into three boundary constructs: i) reputation management; ii) ownership and control, and; iii) accountability. Reputation management defined boundaries are the narrowest, and based on selective content which is often self-laudatory. Accountability defined boundaries are the widest and either acknowledge organisational impact of environmental, social or economic factors through time, beyond the organizational boundary, or through the acceptance of responsibility towards external stakeholders.

The empirical analysis explored definitions of boundary that have been adopted in practice. As organizations rarely disclose their approach to boundary definitions, content analysis of CSR disclosure was used as a proxy for boundary determination. In light of recent developments in CSR guidance advice to adopt an issue-by-issue boundary definition, we focused the content analysis around GRI indicators that were capable of being coded across all three boundary constructs and deemed to be material for the aviation sector (e.g. impact on biodiversity, noise pollution, supply chain issues etc.). In addition, data was analysed on GRI compliance, stakeholder engagement and boundary disclosure to explore the relationship between these variables and boundary construct in practice.

The findings from the content analysis indicate that the overall CSR disclosure within the airline sector is weak, particularly with regards to economic and environmental indicators. Boundary was found to vary from issue to issue, however there was limited evidence that this 
was predicated from an adoption of an aspect boundary approach, but instead was driven by the practicalities of measurement or through regulatory pressures e.g. GHG disclosure, or addressing requirements of the Modern Slavery Act. The average boundary selected across all 22 indicators reviewed was based on a narrow focus and cherry-picked content $(0.3364 \pm$ 0.2226). This may be a consequence of the lack of focus on indirect impacts by guidance providers, despite the fact that most guidance is predicated on the basis of increasing transparency and promoting best practice. This indicates that there is further scope for guidance to promote wider reporting boundaries to inform practice. In addition, given that boundary determination impacts reporting content, and the interpretation of this content, there should be stronger advice to corporations to specify the boundaries used in CSR reporting.

In relation to the historic development of the boundary concept, with the exception of the GRI (2000; 2002; 2006) and the UNGC (2009), all guidance published before 2010 failed to discuss the concept of boundary, either assuming a financial reporting boundary, or not considering the issue significant for consistency and credibility of reporting. Post-2011, all guidance addressed boundary definition or discussed issues relevant to boundary setting, demonstrating an increased emphasis placed on boundary determination as a central concept for CSR reporting. This is not reflected in the academic literature, which is conversely characterised by limited explorations of the boundary concept within CSR (see Archel et al., 2008; Pesci and Andrei, 2011).

The boundary concept has been subject to development over time with current thought questioning the blanket adoption of the financial reporting concepts of ownership and control. The GRI has made concerted efforts to move the debate forward. In 2000, it suggested that "an organization may wish to expand its boundaries" (GRI, 2000, p.13). This was revised in 
2002 to recommend that "the most appropriate boundaries...may extend beyond financial reporting boundaries" (GRI, 2002, p.26). By 2006, the GRI issued a requirement that organizations "must consider the range of entities over which it exercises control...and over which it exercises influence" (GRI, 2006, p.12). Recent thought (GRI, 2013; 2016 p.90) goes further still, highlighting the need to reflect boundary on an issue-by-issue basis depending on context of different aspects, although to some extent boundary is conflated with the issue of materiality (the greater the materiality, the wider the boundary).

Accepting that the reporting boundary may differ with different issues makes CSR reporting distinct from financial reporting, in which a constant boundary across the organization's activities is applicable. For example, in the airline industry, safety is a major concern for stakeholders and airlines and therefore warrants inclusion in the CSR reports on grounds of materiality but comprehensive reporting using an ownership and control boundary is probably adequate for the majority of stakeholder's needs. This contrasts with disclosure on child labour or forced labour. This was not presented as such a material issue as safety across the stakeholder materiality matrices published by the sample companies, but given the consequences of abuse outside of the organization, for example through the supply chain, would warrant a wider boundary consideration. Further debate is now needed on how to operationalise the aspect-by-aspect approach, including sharing knowledge and best practice. Comparability and usefulness of CSR reports would also be significantly improved if boundary determination was made a mandatory disclosure for claiming compliance with CSR guidelines, thereby improving transparency and benchmarking.

Given the range of political agendas and objectives evident between CSR guidance a lack of consistency between standards, and over time, was expected. This was found to be the case. 
For example, the Climate Change Reporting Framework explicitly stated that "any departures from the boundary used for financial reporting should be made clear and explained" (CDSB, 2012, p.12), whilst the Communicating Climate Change in Mainstream Report (CDSB, 2013) advocated that boundary should be extended beyond ownership and control to include "upstream and or downstream operations, joint venture partners, supply chain associates and others" (CDSB, 2013, p.12). Whilst appearing to reflect inconsistency this may be evidence of the development of thinking around boundary and the need for greater transparency over how boundaries are determined, which is a welcome development.

In order to enhance the accountability of organizations, the authors believe that the boundary of reporting should be determined by the issues considered. A high quality CSR report should, firstly, report on all material issues. Secondly, the nature of reporting may feasibly extend the definition of boundary for some material aspects but may retain a narrow conceptualisation for other material impacts. This decision should not be determined by public relations perceptions but should be guided by stakeholder concerns and an assessment of where, inside or outside of the organization, control of the issue lies in order to demonstrate responsibility through transparency and accountability. This may, however, be restricted in practice due to the availability of data and associated accounting methodologies. Consequently, traditional content analysis, in which disclosure content is scored depending on extent of disclosure, may provide misleading results if not supported by an assessment of boundary determination and/or a mixed methods approach to capture the qualitative analysis of the materials. Likewise, any future advances in measurement methodologies would also require a clear conceptual framing of boundary settings.

The study is exploratory in nature and has focused on a small sample size from one industry. The results indicate that there is a lack of conceptual clarification of boundary both between 
guidance provisions and within practice. The content analysis of the CSR reports for the airline industry demonstrates that the definition of boundary used is narrow, restricting the range and scope of reporting. Little is known of the definition of boundary across sectors, and whilst the current results may not be generalizable, given that boundary definition should be sector related, further research is required to confirm or refute this proposition. Consequently, future research could explore a wider range of industries and across a broader time horizon. There is also considerable scope for further conceptual analysis of the boundary construct. We have defined 3 boundary definitions, but admit that the widest instantiation, accountability, could be subject to further refinement to differentiate the value chain, responsibility and time dimensions as separate determinants. 


\section{References}

AccountAbility AA1000 (2008) AA1000 Accountability Principles Standard Retrieved from http://www.accountability.org/standards/ (accessed 1 December 2016)

Aras, G. \& Crowther, D. (2008). Developing sustainable reporting standards. Journal of Applied Accounting Research, 9, 4-16. doi: 10.1108/09675420810886097

Archel, P., Fernández, M., \& Larrinaga, C. (2008). The organizational and operational boundaries of triple bottom line reporting: a survey. Environmental Management, 41, 106-117. doi: 10.1007/s00267-007-9029-7

Bebbington, J., Larrinaga, C., \& Moneva, J. M. (2008). Corporate social reporting and reputation risk management. Accounting, Auditing \& Accountability Journal, 21, 337361. doi.org/10.1108/09513570810863932

Bellantuono, N., Pontrandolfo, P. and Scozzi, B. (2016). Capturing the Stakeholders' View in Sustainability Reporting: A Novel Approach, Sustainability, 8, 379-91. doi:10.3390/su8040379

Brown, H., de Jong, M. and Levy, D. (2009). Building institutions based on information disclosure: lessons from GRI's sustainability reporting. Journal of Cleaner Production, 17, 571-580. doi: 10.1016/j.jclepro.2008.12.009

Business in the Community (BITC) (2005). A Director's Guide to Corporate Responsibility Reporting. Retrieved from http://www.bitc.org.uk/our-resources/report/directorsguide-corporate-responsibility-reporting (accessed 25 November 2016)

Chang, Y. and Yeh, C. (2016). Managing corporate social responsibility strategies of airports: The case of Taiwan's Taoyuan International Airport Corporation. Transportation Research Part A, 92, 338-348. doi: 10.1016/j.tra.2016.06.015

Civil Aviation Authority (CAA) (2015) Aviation's impact on biodiversity Retrieved from https://www.caa.co.uk/Environment/Environmental-information/Information-byenvironmental-impact/Local-impact/Aviation-s-impact-on-biodiversity/ (accessed 15 January 2017)

Climate Disclosure Standards Board (CDSB) (2013). Communicating Climate Change in Mainstream Reports Retrieved from http://www.cdsb.net/sites/cdsbnet/files/cdsbframeworkguidev1_0_2.pdf (accessed 1 December 2016)

Climate Disclosure Standards Board (CDSB) (2012) 'Climate Change Reporting Framework Edition 1.1' Retrieved from http://www.cdsb.net/sites/cdsbnet/files/cdsb_climate_change_reporting_framework_e dition_1.1.pdf (accessed 25 November 2016)

Climate Disclosure Standards Board (CDSB) (2015) Framework for reporting environmental information \& natural capital Retrieved from http://www.cdsb.net/sites/cdsbnet/files/cdsb framework for reporting environmental 
information_natural_capital.pdf (accessed 1 December 2016)

Cooper, S. and Owen, D. (2007). Corporate social reporting and stakeholder accountability: The missing link. Accounting, Organizations and Society, 32, 649-667. doi: 0.1016/j.aos.2007.02.001

Cowper-Smith, A. and de Grosbois, D. (2011). The adoption of corporate social responsibility practices in the airline industry. Journal of Sustainable Tourism, 19, 59-77. doi: $10.1080 / 09669582.2010 .498918$

de Grosbois, D. (2012). Corporate social responsibility reporting by the global hotel industry: Commitment, initiatives and performance. International Journal of Hospitality Management, 31, 896-905. doi: 10.1016/j.ijhm.2011.10.008

de Jonge, A. (2011). Transnational corporations and international law: bringing THCs out of the accountability vacuum. Critical Perspectives on International Business, 7, 66-89. doi: $10.1108 / 17422041111103840$

Etzion, D. and Ferraro, F. (2010). The Role of Analogy in the Institutionalization of Sustainability Reporting. Organization Science, 21, 1092-1107. doi: 10.1287/orsc.1090.0494

European Union (2011). A renewed EU strategy 2011-14 for Corporate Social Responsibility, Retrieved from http://ec.europa.eu/geninfo/query/index.do?queryText=renewed+strategy+2011+$2014+$ CSR\&summary $=$ summary\&more options source $=$ global\&more options date $=$ 0 \&more options date from $=2010-12-31 \&$ more options date to $=2012-12$ -

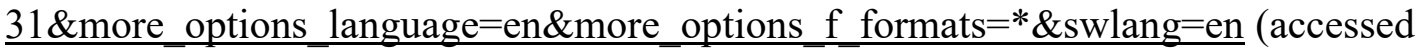
25 November 2016)

Financial Reporting Council (2009) 'Rising to the Challenge; A review of Narrative Reporting by UK listed Companies' Retrieved from https://www.frc.org.uk/OurWork/Publications/ASB/Rising-to-the-Challenge/Rising-to-the-challenge.aspx (accessed 1 December 2016)

Font, X., Walmsley, A., Cogotti, S., McCombes, L. and Hausler, N. (2012). Corporate social responsibility: The disclosure-performance gap. Tourism Management, 33, 1544-1553. doi: 10.1016/j.tourman.2012.02.012

Fortanier, F., Kolk, A. and Pinkse, J. (2011). Harmonization in CSR Reporting MNEs and Global CSR Standards. Management International Review, 51, 665-696. doi: $10.1007 / \mathrm{s} 11575-011-0089-9$

Friedman, A.L. and Miles, S. (2006). Stakeholders: Theory and Practice. Oxford: Oxford University Press.

Global Reporting Initiative (GRI), (2000) Sustainability Reporting Guidelines Global Reporting Initiative Boston MA

Global Reporting Initiative (GRI), (2002) Sustainability Reporting Guidelines Global Reporting Initiative Boston MA 
Global Reporting Initiative (GRI), (2006) Sustainability Reporting Guidelines version 3.1 Retrieved from https://www.globalreporting.org/resourcelibrary/G3.1-Guidelines-InclTechnical-Protocol.pdf (accessed 25 November 2016)

Global Reporting Initiative (GRI), (2013) Sustainability Reporting Guidelines, version 4, available from https://www.globalreporting.org/resourcelibrary/GRIG4-Part1Reporting-Principles-and-Standard-Disclosures.pdf (accessed 25 August 2016)

Global Reporting Initiative (GRI), (2016) Consolidated Sustainability Reporting Guidelines 2016, Retrieved from https://www.globalreporting.org/standards/gri-standardsdownload-center/?g=2d2b941c-df6f-4c73-a874-443f42a5d91a (accessed 31 January 2017)

Gowthorpe, C. (2009). Wider still and wider? A critical discussion of intellectual capital recognition, measurement and control in a boundary theoretical context. Critical Perspectives on Accounting, 20, 823-834. doi:10.1016/j.cpa.2008.09.005

Grandori A. (2000). Organization and Economic Behaviour. London and New York: Routledge; 2000.

Gray, R. (2006). Social, environmental and sustainability reporting and organizational value creation? Whose value? Whose creation? Accounting, Auditing \& Accountability Journal, 19, 793-819. doi: 10.1108/09513570610709872

Hammond, K. and Miles, S. (2004). Assessing quality assessment of corporate social reporting: UK perspectives. Accounting Forum, 28, 61-79. doi:

10.1016/j.accfor.2004.04.005

International Accounting Standards Board (IASB) (2011) IFRS 10 Consolidated Financial Statements, London:IASB

International Air Transport Association (IATA) (2016a) Fact sheet Economic and Social Benefits of Air Transport available from http://www.iata.org/pressroom/facts figures/fact sheets/Documents/fact-sheetindustry-facts.pdf accessed on 28 Noveber 2016

International Air Transport Association (IATA) (2016b) Fact sheet Industry Statistics Retrived from from http://www.iata.org/pressroom/facts figures/fact sheets/Documents/fact-sheetindustry-facts.pdf (accessed on 28 November 2016)

International Corporate Governance Network (ICGN) (2008) 'Statement and Guidance on Non-Financial Business Reporting Retrieved from https://www.icgn.org/sites/default/files/ICGN\%20NFBR\%20Guidance\%20\%282008 \%29 re-print\%20May2013_FULL_0.pdf (accessed 1 December 2016)

International Financial Reporting Standards Foundation (IFRS) (2010) 'Management Commentary, A Framework for Presentation' Retrieved from http://www.ifrs.org/Current-Projects/IASB-Projects/Management-Commentary/IFRSPractice$\underline{\text { Statement/Documents/Managementcommentarypracticestatement8December.pdf }}$ 
(accessed 1 December 2016)

International Integrated Reporting Council (IIRC) (2013) International Integrated Reporting Framework Retrieved from https://integratedreporting.org/wpcontent/uploads/2013/12/13-12-08-THE-INTERNATIONAL-IR-FRAMEWORK-21.pdf (accessed 25 November 2016)

International Standard on Assurance Engagements (ISAE) (2013), ISAE 3000 (Revised) Assurance Engagements Other than Audits or Reviews of Historical Financial Information Retrieved from https://www.ifac.org/publications-resources/internationalstandard-assurance-engagements-isae-3000-revised-assurance-enga (accessed 1 December 2016)

International Standard Organization (ISO) (2010) 'ISO 26000, Schematic overview' Retrieved from http://www.iso.org/iso/sr_schematic-overview.pdf (accessed 1 December 2016)

International Standard Organization (ISO) (2014) Discovering ISO 26000 Guidance on social responsibility Retrieved from http://www.iso.org/iso/discovering_iso 26000.pdf (accessed 1 December 2016)

Khan, M., Serafeim, G. and Yoon, A. (2016) Corporate Sustainability: First Evidence on Materiality. The Accounting Review, 91, 1697-1724. doi: 10.2308/accr-51383

KPMG (2015). Currents of Change: The KPMG survey of Corporate Responsibility Reporting 2015. Retrieved from https:/home.kpmg.com/xx/en/home/insights/2015/11/kpmg-international-survey-ofcorporate-responsibility-reporting-2015.html (accessed 15 November 2016)

Kuo, T., Kremer, G., Phuong, N. and Hsu, C. (2016). Motivations and barriers for corporate social responsibility reporting: Evidence from the airline industry. Journal of Air Transport Management, 57, 184-195. doi: 10.1016/j.jairtraman.2016.08.003

Lindblom C., (1994). 'The implications of organizational legitimacy for corporate social performance and disclosure', paper presented at critical perspectives on accounting conference, New York

Llewellyn, S. (1994). Managing the Boundary: How Accounting Is Implicated in Maintaining the Organization. Accounting, Auditing \& Accountability Journal, 7, 4 - 23. doi: 10.1108/09513579410069821

Manetti, G. (2011). The quality of stakeholder engagement in sustainability reports: empirical evidence and critical points. Corporate Social Responsibility and Environmental Management, 18, 110-122. doi: 10.1002/csr.255

Michelon, G., Pilonato, S., Ricceri, F. (2015). CSR reporting practices and the quality of disclosure: An empirical analysis. Critical Perspectives on Accounting, 33, 59-78. doi: 10.1016/j.cpa.2014.10.003

Milne, M. and Alder, R. (1999). Exploring the reliability of social and environmental 
disclosures content analysis. Accounting, Auditing and Accountability Journal, 12, 237-256. doi: 10.1108/09513579910270138

Milne, M. and Gray, R. (2013). W(h)ither Ecology? The Triple Bottom Line, the Global Reporting Initiative, and Corporate Sustainability Reporting. Journal of Business Ethics, 118, 13-29. doi: 10.1007/s10551-012-1543-8

Morgan, G. (1986). Images of Organizations, Sage, London.

O'Dwyer, B. (2000). Evidence and the public interest versus expediency: critical commentary on "Could corporate environmental reporting shadow financial reporting?" by Aris Solomon. Accounting Forum, 24, 223-230.

O'Dwyer, B. (2003). Conceptions of corporate social responsibility: the nature of managerial capture. Accounting, Auditing \& Accountability Journal. 16, 523-557. doi:10.1108/09513570310492290.

Organization for Economic Co-operation and Development (OECD) (2011). Guidelines for Multinational Enterprises, Retrieved from https://www.oecd.org/corporate/mne/48004323.pdf (accessed 25 November 2016)

Owen, D. (2008). Chronicles of wasted time? Accounting, Auditing \& Accountability Journal, 21, 240-267. doi: 10.1108/09513570810854428

Pesci, C. and Andrei, P. (2011). An empirical investigation into the boundary of corporate social reports and consolidated financial statements. Social and Environmental Accountability Journal, 31, 73-84. doi: 10.1080/0969160X.2011.556404

Puma (2011) Environmental Profit and Loss Account retrieved from http://about.puma.com/damfiles/default/sustainability/environment/e-p1/EPL080212final-3cdfc1bdca0821c6ec1cf4b89935bb5f.pdf (accessed 16 January 2017)

Sethi, S., Martell, T. and Demir, M. (2017). An Evaluation of the Quality of Corporate Social Responsibility Reports by Some of the World's Largest Financial Institutions. Journal of Business Ethics. 140, 787-805. doi: 10.1007/s10551-015-2878-8

Sustainability Accounting Standards Board(SASB) (2016) Implementation Guide 1.1 Retrieved from http://using.sasb.org/index/for-companies/for-companies-get-started/ accessed 28 November 2016

United Nations Conference on Trade and Development (UNCTD) (2008) Guidance on Corporate Responsibility Indicators in Annual Reports Retrieved from http://unctad.org/en/docs/iteteb20076 en.pdf (accessed 1 December 2016)

United Nations Global Compact (UNGC) (2013) 'UN Global Compact Policy on Communicating Progress' Retrieved from https://www.unglobalcompact.org/docs/communication_on_progress/COP_Policy.pdf (accessed 25 November 2016) 
United Nations Global Compact (UNGC) (2009) 'The Practical Guide to the UN Global Compact Communication On Progress' retrieved from http://www.undp.org/content/dam/turkey/docs/Publications/PovRed/Practical_Guide 2008 En.pdf (accessed 1 December 2016)

United Nations (UN) (2006) 'Principles for Responsible Investment' Retrieved from https://www.unpri.org/about/the-six-principles (accessed 1 December 2016) 
Figure 1: Application of Aspect Boundary setting definition of 22 GRI indicators in CSR reports of Airline Companies (Scale 0-1)

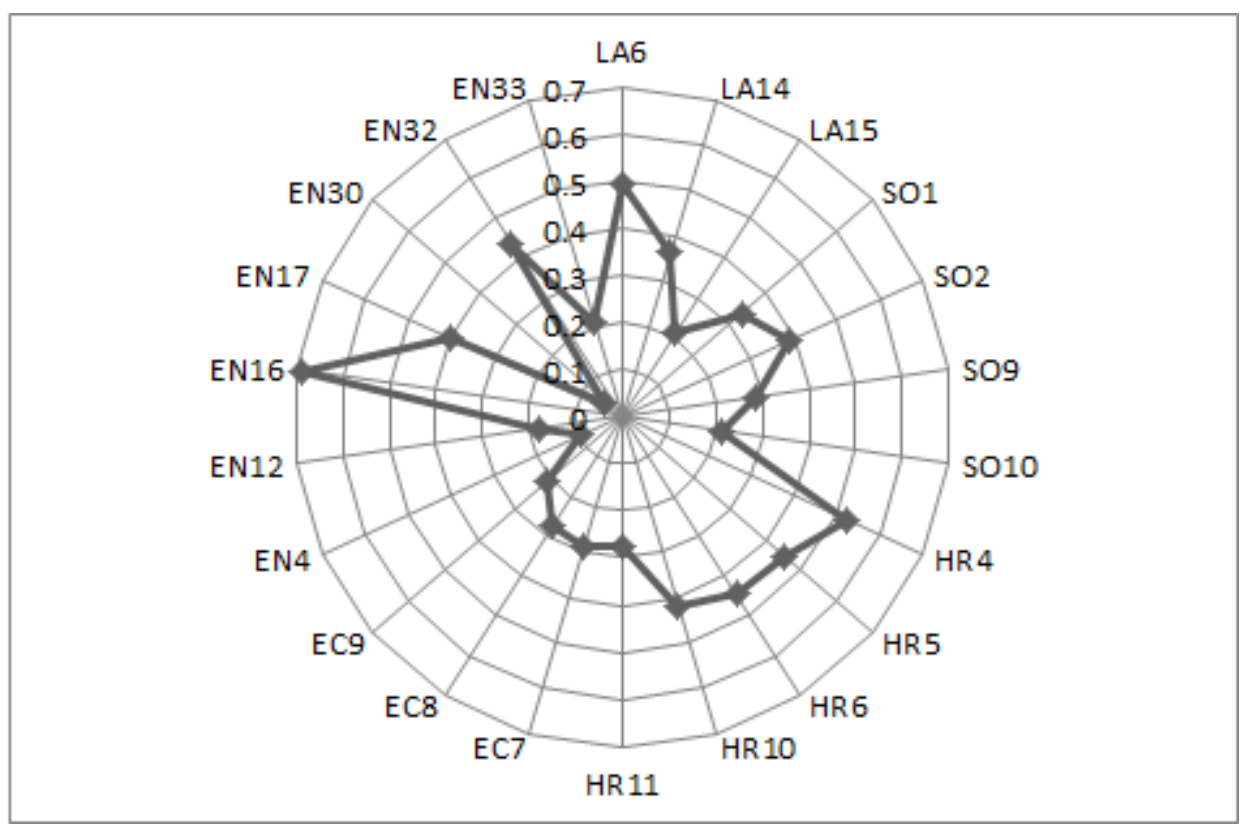


Table 1: Boundary Categorisations Derived from CSR Guidance

\begin{tabular}{|c|c|c|}
\hline $\begin{array}{c}\text { Boundary } \\
\text { Categorisation }\end{array}$ & Themes and Subthemes Derived from CSR Guidance & $\begin{array}{c}\text { Reporting content and } \\
\text { Boundary } \\
\text { Implications }\end{array}$ \\
\hline \multirow{5}{*}{$\begin{array}{c}\text { Reputation } \\
\text { Management }\end{array}$} & 1. Competitive advantage, drivers and opportunities & \multirow{5}{*}{$\begin{array}{l}\text { Narrow boundary } \\
\text { determination. } \\
\text { Selective content } \\
\text { Cherry picked } \\
\text { Self-laudatory }\end{array}$} \\
\hline & 2. Industry expectations and norms & \\
\hline & 3. Risk assessment & \\
\hline & $\begin{array}{l}\text { 4. Stakeholder concerns (selective) } \\
\text { 5. Public policy dialogue and advocacy } \\
6 \text { Community interaction, social investment, } \\
\text { philanthropy activities } \\
\text { 7. Political or other relationships }\end{array}$ & \\
\hline & $\begin{array}{l}\text { Scope (selective) } \\
\text { 8. Geographic region } \\
\text { 9. Business unit } \\
\text { 10. Individual site } \\
\text { 11. Company }\end{array}$ & \\
\hline $\begin{array}{c}\text { Ownership } \\
\text { and } \\
\text { Control }\end{array}$ & $\begin{array}{l}\text { 12. Financial Accounting } \\
\text { 13. Legal ownership } \\
\text { 14. Equity share } \\
\text { 15. Joint ventures } \\
\text { 16. Partnerships } \\
\text { 17. Associates } \\
\text { 18. Control } \\
\text { 19. Group } \\
\text { 20. Subsidiaries } \\
\text { 21. Significant or Substantive Influence } \\
\text { 22. Organizational boundary } \\
\text { 23. Within the organization } \\
\text { 24. Core activities } \\
\text { 25. Direct impacts } \\
\text { 26. Contractual/business relationships }\end{array}$ & $\begin{array}{c}\text { Organizational } \\
\text { Boundary } \\
\text { determination based } \\
\text { on significant influence } \\
\text { and direct impact } \\
\text { derived from } \\
\text { ownership and control }\end{array}$ \\
\hline
\end{tabular}


Table 1 (continued): Boundary Categorisations Derived from CSR Guidance

\begin{tabular}{|l|c|c|}
\hline & 27. Operational boundary (holistic scope) & \\
28. Indirect impact & \\
29. Near or medium term impacts & \\
30. Upstream Activities & \\
31. Supply Chain & \\
32. Subcontractors & \\
33. Outsourced activities & Wide boundary \\
Accountability & 34. Downstream Activities & on influence and \\
35. Distributors and users & indirect impact \\
36. Life cycle & \\
37. Outside the organization & \\
38. Stakeholder concerns (holistic) & \\
39. Responsibility & \\
40. Influence & \\
&
\end{tabular}


Table 2: Airline Companies Sampled

\begin{tabular}{|c|c|c|c|c|c|c|c|}
\hline Company & CSR Report & Country & GRI 3/4 & Company & CSR Report & Country & GRI 3/4 \\
\hline Aeronas de Mexico & 2014 & Mexico & yes & FAI & 2014 & Germany & yes \\
\hline Air Canada & 2014 & Canada & yes & Finnair & 2013 & Finland & yes \\
\hline Air China & 2014 & China & yes & GOL & 2014 & Brazil & yes \\
\hline Air France - KLM & 2014 & France & yes & Japan & 2014 & Japan & no \\
\hline All Nippon Airways & 2015 & Japan & no & Korean & 2014 & Korea & yes \\
\hline Asiana Airways & 2015 & Korea & yes & Quantas & 2015 & Australia & yes \\
\hline British Airways & $2014 / 15$ & UK & yes & Singapore & 2015 & Singapore & yes \\
\hline Cargolux & 2014 & Luxembourg & yes & Southwest & 2014 & USA & yes \\
\hline China Eastern Airways & 2014 & China & yes & Thai Airways & 2014 & Thailand & yes \\
\hline China Southern Airways & 2014 & China & yes & SAS & 2014 & Scandinavia & yes \\
\hline Comair (Integrated Report) & 2015 & South Africa & yes & Turk Hava & 2014 & Turkey & yes \\
\hline Controladora & 2014 & Mexico & yes & Virgin Atlantic & 2015 & UK & no \\
\hline Delta Air & 2014 & USA & yes & Virgin Australia & 2015 & Australia & no \\
\hline Deutshe Lufthansa & 2014 & Germany & no & Westjet & 2014 & Canada & yes \\
\hline Easyjet & 2014 & UK & no & Xiamen & 2014 & China & yes \\
\hline Ethiad & 2012 & UAE & yes & & & & \\
\hline
\end{tabular}


Table 3: GRI indicators used for Content Analysis

\begin{tabular}{|c|c|c|c|}
\hline $\begin{array}{c}\text { GRI } \\
(2013)\end{array}$ & $\begin{array}{c}\text { GRI } \\
(2016)\end{array}$ & Summary Description & Significance to aviation sector \\
\hline \multicolumn{4}{|l|}{ Labour } \\
\hline LA6 & $403-2$ & $\begin{array}{l}\text { Type of Injury, rates of injury, occupational diseases, lost days, absenteeism, total number of work- } \\
\text { related fatalities }\end{array}$ & $\begin{array}{l}\text { Safety of staff and passengers considered a high } \\
\text { priority. Injuries stem from lifting and handling, } \\
\text { slip, trip, struck, falling from height, vehicle } \\
\text { accidents etc. }\end{array}$ \\
\hline LA14 & $414-1$ & $\%$ new suppliers screened using labour practices criteria & \multirow{2}{*}{$\begin{array}{l}\text { Instances of poor labour practice can quickly resul } \\
\text { in industrial conflict due to high levels of union } \\
\text { density and complexity of industrial relations } \\
\text { structure. Issues are exacerbated by increasing } \\
\text { presence of low cost airlines and complexity of } \\
\text { global supply chain }\end{array}$} \\
\hline LA15 & $414-2$ & $\begin{array}{l}\text { Significant (Actual/potential) negative impacts for labour practices in the supply chain \& actions } \\
\text { taken }\end{array}$ & \\
\hline \multicolumn{4}{|l|}{ Society } \\
\hline $\mathrm{SO} 1$ & $413-1$ & $\begin{array}{l}\% \text { operations with implemented local community engagement, impact assessments \& development } \\
\text { programs }\end{array}$ & \multirow{4}{*}{$\begin{array}{l}\text { Aviation operations can be intrusive for local } \\
\text { communities living close to airports or along flight } \\
\text { path. Issues include disturbance of daily lives and } \\
\text { loss of tranquillity, health implications of unburnt } \\
\text { aviation fuel, fear of loss of house values and road } \\
\text { traffic congestion to and from airports. Issues are } \\
\text { exacerbated by increasing presence of low cost } \\
\text { airlines and complexity of global supply chain }\end{array}$} \\
\hline $\mathrm{SO} 2$ & $413-2$ & Operations with significant (actual/potential) negative impacts on local communities & \\
\hline SO9 & $414-1$ & $\%$ new suppliers screened using criteria for impacts on society & \\
\hline SO10 & $414-2$ & Significant (Actual/potential) negative impacts on society in the supply chain $\&$ actions taken & \\
\hline \multicolumn{4}{|c|}{ Economic } \\
\hline EC7 & $203-1$ & Development \& impact of infrastructure investments \& services supported & \\
\hline EC8 & $203-2$ & Significant indirect economic impacts \& extent of impacts & \\
\hline EC9 & 204-1 & Proportion of spending on local suppliers at significant locations or operations & \\
\hline
\end{tabular}




\section{Table 3: GRI indicators used for Content Analysis (continued)}

\begin{tabular}{|c|c|c|c|}
\hline \multicolumn{4}{|c|}{ Human Rights } \\
\hline HR4 & $407-1$ & $\begin{array}{l}\text { Operations \& suppliers identified in which the right to exercise freedom of association \& collective } \\
\text { bargaining may be violated or at significant risk, support measures taken }\end{array}$ & $\begin{array}{l}\text { Significant amount of industrial conflict due to high } \\
\text { volume of restructuring, high levels of union } \\
\text { density and complexity of industrial relations } \\
\text { structure }\end{array}$ \\
\hline HR5 & $408-1$ & $\begin{array}{l}\text { Operations \& suppliers identified as having significant risk for incidents of child labour, measures } \\
\text { taken to contribute to effective abolition of child labour }\end{array}$ & \multirow{4}{*}{$\begin{array}{l}\text { Airline employees, contractors and flight attendants } \\
\text { are at the front line to fight against human } \\
\text { trafficking and specifically the sexual exploitation } \\
\text { and slavery of children. Issues are exacerbated by } \\
\text { complexity of global supply chain }\end{array}$} \\
\hline HR6 & $409-1$ & $\begin{array}{l}\text { Operations \& suppliers identified as having significant risk for incidents of forced compulsory } \\
\text { labour, measures to contribute to elimination of forced compulsory labour }\end{array}$ & \\
\hline HR10 & $414-1$ & $\%$ new suppliers screened using human rights criteria & \\
\hline HR11 & $414-2$ & Significant (Actual/potential) negative human rights impacts in the supply chain \& actions taken & \\
\hline \multicolumn{4}{|c|}{ Environment } \\
\hline EN4 & $302-2$ & Energy consumption outside of the organization & \\
\hline EN12 & $304-2$ & Significant impacts on biodiversity in protected areas $\&$ areas of high biodiversity value & \\
\hline EN16 & $305-2$ & Energy GHG emissions (Scope 2) & \\
\hline EN17 & $305-3$ & Other GHG emissions (Scope 3) & \\
\hline EN30 & $305-1$ & $\begin{array}{l}\text { Significant environmental impacts of transporting products, goods \& materials \& transporting } \\
\text { members of the workforce }\end{array}$ & \\
\hline EN32 & $308-1$ & $\%$ new suppliers screened using environmental criteria & \\
\hline EN33 & $308-2$ & Significant (Actual/potential) negative environmental impacts in the supply chain \& actions taken & \\
\hline
\end{tabular}


Table 4: Descriptive Statistics and Results of Testing (using one-sample t-test) with a Hypothetical Disclosure Mean of 0.4.

Std.

\begin{tabular}{lccccccc} 
Variable & $\boldsymbol{N}$ & Min. & Max. & Mean & Dev. & $\boldsymbol{t}$ & \multicolumn{2}{c}{$\boldsymbol{p}$-value } \\
\hline LABOUR & 35 & 0.000 & 0.889 & 0.356 & 0.294 & 0.885 & 0.382 \\
SOCIETY & 35 & 0.000 & 1.000 & 0.305 & 0.267 & 2.105 & 0.043 \\
RIGHTS & 35 & 0.000 & 1.000 & 0.425 & 0.372 & 0.398 & 0.693 \\
ECON & 35 & 0.000 & 0.583 & 0.193 & 0.206 & 0.554 & 0.583 \\
ENVIRN & 35 & 0.000 & 0.762 & 0.294 & 0.206 & 3.044 & 0.005 \\
\hline
\end{tabular}


TABLE 5: Correlation Analysis for GRI Indicators, Boundary Determination and Stakeholder Consultations.

\begin{tabular}{lrrrrrrr} 
& LABOUR & SOCIETY & RIGHTS & ECON & ENVIRN & BOUND & STAKE \\
\hline LABOUR & 1.000 & & & & & \\
SOCIETY & 0.728 & 1.000 & & & & & \\
RIGHTS & 0.718 & 0.753 & 1.000 & & & & \\
ECON & 0.293 & 0.054 & 0.436 & 1.000 & & \\
ENVIRN & 0.526 & 0.460 & 0.714 & 0.327 & 1.000 & \\
BOUND & 0.022 & 0.003 & 0.050 & 0.097 & -0.026 & 1.000 & \\
STAKE & -0.128 & -0.342 & -0.019 & 0.279 & -0.169 & 0.148 & 1.000
\end{tabular}




\section{Appendix 1: Chronological Conceptualisation of Boundary in CSR guidance}

GRI (2000:13): "boundary...(e.g. equity share, management control, site, company, group). GRI reporters may choose to use the traditional financial accounting and reporting boundary definition as a starting point....It is important...to define the organization boundaries in a way that assures readers that the originator of, or contributor to, the material impacts of its activities is included within those boundaries. ...An organization may wish to expand its boundaries in subsequent GRI reports to capture upstream and downstream effects of its products and services. ... Organizations that form part of a supply chain... may require addressing in some way the total life-cycle impact of the product or service from resource extraction to end of life"

GRI (2002:26): These boundaries should be selected with consideration of the economic, environmental and social impacts of the organization. Such boundaries may be defined based on financial control, legal ownership, business relationships and other considerations. ... in some cases, the most appropriate boundaries .... may extend beyond traditional financial reporting boundaries".

GRI (2006:12): “'Boundary' refers to the range of entities (e.g., subsidiaries, joint ventures, sub-contractors, etc.) whose performance is represented by the report. In setting the boundary for its report, an organization must consider the range of entities over which it exercises control (often referred to as the 'organizational boundary', and usually linked to definitions used in financial reporting) and over which it exercises influence (often called the 'operational boundary'). In assessing influence, the organization will need to consider its ability to influence entities upstream (e.g., in its supply chain) as well as entities downstream (e.g., distributors and users of its products and services). The boundary may vary based on the specific Aspect or type of information being reported."

UN Global Compact (2009:8): “...described as spheres of influence, and envisioned as a series of concentric circles, where influence diminishes as the circles get bigger. The smallest circle includes a company's core business activities in the workplace and marketplace. This is where a company has the greatest control in affecting ESG (environmental, social and governance) performance. The next circle covers the supply chain. Control is weakened here, but in some cases the influence can be significant. The third circle includes a company's community interaction, social investment and philanthropy activities. And the final circle of influence is a company's engagement in public policy dialogue and advocacy activities."

IFRS (2010:5): "management commentary lies within the boundaries of financial reporting"

ISO (2010:2.19): "sphere of influence: range/extent of political, contractual, economic or other relationships through which an organization ....has the ability to affect the decisions or activities of individuals or organizations."

GRI (2011): As per GRI (2006)

CDSB (2012:9): Subject to the CCRF recommendations about organizational boundaries for greenhouse gas emissions reporting ...disclosures shall be made for the organization for which consolidated financial statements are prepared.

CDSB (2012:23): “approach to organizational boundary setting aligns to boundaries used for financial reporting purposes so that GHG emissions are reported for the same entities as those for which financial statements are produced." 
CDSB (2013:11): “ $\ldots$ whether a business unit, particular geography or other, over which the organization has full control, significant influence and power to affect and/or is regarded as responsible for performance”. CDSB (2013:12): “...may include the parent company, its subsidiaries, upstream and/or downstream operations, joint venture partners, supply chain associates and others .... approach to boundary-setting, according to the type of control and influence exercised by a reporter over an entity, which may be (i) financial, (ii) operational and/or (iii) an equity share."

GRI (2013:92): “... where impacts occur for each material Aspect. In setting the Aspect Boundaries, an organization should consider impacts within and outside of the organization. Aspect Boundaries vary based on the Aspects reported."

IIRC (2013:19): “...two aspects: Financial reporting entity (i.e., the boundary used for financial reporting purposes) and risks, opportunities and outcomes attributable to or associated with other entities/stakeholders beyond the financial reporting entity that have a significant effect on the ability of the financial reporting entity to create value"

ISAE 3000 (2013:124): “a choice between an approach that aligns the entity's GHG statement with its financial statements and another approach that treats, for example, joint ventures or associates differently. Determining ... boundary may require the analysis of complex organizational structures such as joint ventures, partnerships, and trusts, and complex or unusual contractual relationships. For example, a facility may be owned by one party, operated by another, and process materials solely for another party"

CDSB (2015:18): “...for which the mainstream report is prepared and, where appropriate, shall distinguish information reported for entities and activities outside that boundary" CDSB (2015:22): "Where sources of environmental impact originate outside the organization's reporting boundary as a result of contractual or other relationships between the reporting organization and third parties (e.g.: indirect or scope 3 GHG emissions in the supply chain), the provision of quantitative information is encouraged where material to the reporting organization, but is not required”. CDSB (2015:24): “... environmental information outside the organization's mainstream reporting boundary may be disclosed for a variety of reasons, including: *The reporting organization is required or chooses to report on activities for which it is responsible (whether or not within the mainstream reporting boundary) for example, outsourced activities; *Due to the nature of the contract for the operation or use of or services procured from the entity or facility, the reporting organization is exposed to material risk, opportunity or financial impact; and *The reporting organization has the power to influence its environmental impacts."

SASB (2016:11): Five factor test "Direct financial impacts \& risks: ...the likelihood that corporate performance on the topic will have a direct and measurable impact on near- or medium-term financial performance. Legal, regulatory \& policy drivers: Existing, evolving, or emerging regulation may influence company actions and affect financial performance by forcing the internalization of certain costs and/or by creating upside opportunity associated with sustainability-related externalities. Industry norms, best practice \& competitive drivers: Peer actions and disclosure on industry issues may create pressure for high standards of performance related to the management and disclosure of sustainability topics in order to remain competitive and satisfy investors. Stakeholder concerns and social trends: Stakeholders may raise concerns that could influence medium- or long-term financial or operating performance or create acute short-term financial impacts through changes in customer demand, influence on new regulations, and disruptions to business viability. Opportunities for innovation: New products and business models to address the topic can drive market expansion or have the potential for a disruptive change that provides new sources of competitive advantage. Financial impacts and risks 


\begin{tabular}{|l|}
\hline associated with these innovations may be of interest to investors." \\
\hline GRI (2016:11): “description of where the impacts occur for a material topic, and the organization's involvement with those impacts" Where a material topic "reflects a \\
reporting organization's significant economic, environmental and social impacts; or that substantively influences the assessments and decisions of stakeholders". \\
GRI (2016:17): "topic boundaries vary based on the topics reported"
\end{tabular}

